\title{
TRABAJADORES MIGRANTES EN MÉXICO: ANÁLISIS NORMATIVO
}

\section{MIGRANT WORKERS IN MEXICO: NORMATIVE ANALYSIS}

\author{
Alfredo Islas Colín \\ Universidad Juárez Autónoma de Tabasco, Tabasco. México/Mexico \\ islas40@hotmail.com
}

Recibido/Received: 29/04/2017

Modificado/Modified: 30/06/2017

Aceptado/Accepted: 27/09/2017

\section{RESUMEN}

Se analizan las normas jurídicas que determinan los límites y alcances de los derechos humanos de los trabajadores migrantes en México a la luz del método documental contrastante y su evolución con la finalidad de conocer la adecuación de las normas constitucionales que contienen derechos de migrantes a la Convención Internacional sobre Protección de los Derechos de todos los Trabajadores Migratorios y sus Familiares y las normas derivadas de éstas normas, las normas de origen interno y externo, así como, las resoluciones emitidas por las Naciones Unidas. Se observa que México ha reformado la Carta Fundamental para adecuarla a los criterios internacionales y celebrado diversos tratados internacionales para proteger adecuadamente a los trabajadores migrantes y familiares.

\section{PALABRAS CLAVE}

Migrantes; trabajadores; instrumentos internacionales; Derechos Humanos; grupos vulnerables.

\section{SUMARIO}

1. Introducción. 2. El Estado mexicano como impulsor de la protección de derechos humanos de migrantes. 2.1. Tratados. 2.2. Legislación. 2.3. Programas. 3. Resoluciones de la Asamblea General de la ONU para la protección de migrantes. 3.1 Instrumentos Internacionales. 3.2. Grupos vulnerables. 3.2.1. Trabajadores migratorios. 3.2.2. Mujeres y niños. 3.2.3. Sujetos de obligaciones. 4. Conclusiones. Bibliografía.

\begin{abstract}
It analyzes the legal norms that determine the limits and scope of the human rights of migrants in Mexico in the light of the contrasting documentary method and its evolution in order to know the adequacy of the constitutional norms that contain rights of migrants to the International Convention On the Protection of the Rights of All Migrant Workers and Members of Their Families and the norms derived therefrom, norms of internal and external origin, as well as resolutions issued by the United Nations. It is noted that Mexico has reformed the Basic Charter to bring it into line with international standards, and has signed various international treaties to adequately protect migrant and family workers.
\end{abstract}

\section{KEYWORDS}

Migrants; Workers; international instruments; Human Rights; vulnerable groups. 


\section{CONTENTS}

1. Introduction. 2. The Mexican State as promoter of the protection of the human rights of migrants. 2.1. Treaties. 2.2. Legislation. 2.3. Programs. 3. Resolutions of the UN General Assembly for the protection of migrants. 3.1 International Instruments. 3.2. Vulnerable groups. 3.2.1. Migrant workers. 3.2.2. Women and children. 3.2.3. Subjects of obligations. 4. Serious human rights violations against migrants and their families. 5. Conclusions. References.

\section{INTRODUCCIÓN}

A continuación analizaremos los derechos de los migrantes trabajadores y su familia a la luz de la legislación de origen interno y externo del Estado mexicano y las resoluciones de las Naciones Unidas. Se considera trabajador migrante a toda aquella "persona que vaya a realizar, realice o haya realizado una actividad remunerada en un Estado del que no sea nacional..." de conformidad con el artículo 2 de la Convención Internacional sobre Protección de los Derechos de todos los Trabajadores Migratorios y sus Familiares (Convención). La protección internacional, es también, para los "familiares" de los trabajadores migrantes, los cuales comprenden aquellas "personas casadas con trabajadores migratorios o que mantengan con ellos una relación que, de conformidad con el derecho aplicable, produzca efectos equivalentes al matrimonio, así como a los hijos a su cargo y a otras personas a su cargo reconocidas como familiares por la legislación aplicable o por acuerdos bilaterales o multilaterales aplicables entre los Estados de que se trate", de conformidad al artículo. 4 de la citada Convención.

El organismo internacional responsable de observar la aplicación de la Convención de referencia, es el Comité de Protección de los Derechos de todos los Trabajadores Migratorios y de sus Familiares (CMW) de la ONU, conforme al artículo 72 de la Convención citada. De conformidad con la Constitución Política de los Estados Unidos Mexicanos (CPEUM), los migrantes tienen los mismos derechos que los nacionales debido a que dicha Carta Fundamental prevé que todas las personas, sin distinción alguna, podrá gozar de los derechos previstos tanto en la misma Carta Fundamental, como los previstos en los tratados en los que México sea parte; asimismo, la misma disposición, prohíbe la discriminación por razón de origen nacional (a. 1, de la CPEUM, reforma DOF 100611).

Se consideran personas extranjeras aquellos que no son del Estado nacional donde se localizan, en éste sentido son extranjeros aquellos "que no tienen la nacionalidad por nacimiento", ius solis o ius sanguinis o aquellos que "no obtuvieron la nacionalidad por naturalización", en cumplimiento al artículo 30 de la CPEUM.

Se prohíbe la esclavitud en el territorio nacional, por lo que aquellos que provengan del extranjero, obtendrán su libertad inmediata y tendrán la protección de las leyes nacionales, artículo 1, párrafo 4 de la Carta Fundamental; asimismo, se otorga a todas las personas la libertad de tránsito y residencia, de conformidad al artículo 11 de la Carta Fundamental mexicana, lo que comprende los migrantes y familiares, de entrar y salir libremente por el territorio nacional.

Los derechos humanos de los migrantes y sus familiares están previstos en los Tratados internacionales de los que México es parte, y aquellos otros instrumentos internacionales que a continuación se exponen. El orden de exposición de los derechos humanos de los trabajadores migrantes es en dos partes: en la primera parte, presentamos conforme a un orden de jerarquía normativa, primero, en el numeral 2, los derechos humanos de los 
trabajadores migrantes y sus familias previstos en los tratados internacionales suscritos por el Estado mexicano; luego la legislación expedida y reformada; y a continuación, los programas aprobados sobre esta materia. En cada apartado se reflexiona sobre su grado de cumplimiento. En una segunda parte, en el numeral 3, se sistematiza, las resoluciones de la ONU para la protección de migrantes, primero los grupos vulnerables como son los trabajadores migratorios y después de manera específica los las mujeres y niños y al final, aquellos sujetos que tienen obligaciones con respecto a los migrantes.

\section{EL ESTADO MEXICANO COMO IMPULSOR DE LA PROTECCIÓN DE DERECHOS HUMANOS DE MIGRANTES}

El Estado mexicano ante el número tan elevado de migrantes que pasan por el territorio mexicano ha desplegado diversas acciones tanto en el ámbito internacional como nacional para hacer frente a los problemas que presenta el trato a los migrantes. Las acciones emprendidas por las autoridades mexicanas son desde la celebración de tratados, expedición de leyes y publicación de Programas.

\subsection{Tratados}

La protección de los trabajadores migrantes y sus familias es un compromiso del Estado mexicano al ratificar diversos instrumentos internacionales que la comunidad internacional ha generado, para proteger a los trabajadores migrantes y su familia en sus derechos humanos, tales como el resumen que refleja la tabla 1:

Tabla 1. Instrumentos Internacionales

\begin{tabular}{|l|}
\hline 1. Declaración Universal de Derechos Humanos \\
\hline 2. Pacto Internacional de Derechos Económicos, Sociales y Culturales \\
\hline 3. Pacto Internacional de Derechos Civiles y Políticos \\
\hline 4. Convención sobre los Derechos del Niño \\
\hline $\begin{array}{l}\text { 5. Convención Internacional sobre protección de los derechos de todos los trabajadores } \\
\text { migratorios y sus familiares }\end{array}$ \\
\hline 6. Convención Internacional sobre la Eliminación de Todas las Formas de Discriminación Racial \\
\hline 7. Convención sobre la eliminación de todas las formas de discriminación contra la mujer \\
\hline 8. Convenio relativo al trabajo forzoso u obligatorio, 1930 (OIT, No. 29) \\
\hline 9. Convenio relativo a la abolición del trabajo forzoso, 1957 (OIT, No. 105) \\
\hline $\begin{array}{l}\text { 10. Convención Internacional para la Protección de Todas las Personas contra la Desapariciones } \\
\text { Forzadas, ratificada el 18 de marzo de 2008 }\end{array}$ \\
\hline $\begin{array}{l}\text { 11. Convención sobre los derechos de las personas con discapacidad, ratificada el 17 de diciembre } \\
\text { de 2007 y su Protocolo Facultativo }\end{array}$ \\
\hline $\begin{array}{l}\text { 12. Protocolo Facultativo de la Convención contra la Tortura y Otros Tratos o Penas Crueles, } \\
\text { Inhumanos o Degradantes, ratificado el 11 de abril de 2005 }\end{array}$ \\
\hline 13. Protocolo contra el Tráfico Ilícito de Migrantes por Tierra, Mar y Aire \\
\hline 14. Protocolo para prevenir, reprimir y sancionar la de Personas, especialmente Mujeres y Niños \\
\hline $\begin{array}{l}\text { 15. Segundo Protocolo Facultativo del Pacto Internacional de Derechos Civiles y Políticos relativo } \\
\text { a la abolición de la pena de muerte, ratificación en 2007 }\end{array}$ \\
\hline 16. Recomendación sobre los trabajadores migrantes (OIT, núm. 86) \\
\hline 17. Recomendación sobre los trabajadores migrantes (OIT, núm.151) \\
\hline
\end{tabular}

Además, el Estado mexicano ha contribuido de manera formal para la protección de los derechos humanos al ampliar la competencia y renovar la integración de los organismos 
internacionales que supervisan el cumplimiento de los compromisos internacionales siguientes, véase tabla 2:

Tabla 2. Acuerdos ampliados y renovados por el Estado mexicano

\begin{tabular}{|l|}
\hline $\begin{array}{l}\text { 1. Renovación del mandato del Relator Especial sobre los Derechos Humanos de los Migrantes en } \\
2008\end{array}$ \\
\hline $\begin{array}{l}\text { 2. Aprobación de los párrafos sobre migración en la Declaración y Programa de Acción de la } \\
\text { Conferencia Mundial sobre la Migración y el Desarrollo, en 2008 }\end{array}$ \\
\hline $\begin{array}{l}\text { 3. Aceptación de la competencia para recibir comunicaciones de los particulares al Comité de } \\
\text { Protección de los Derechos de Todos los Trabajadores Migratorios y de sus Familiares (CMW) }\end{array}$ \\
\hline
\end{tabular}

En 2011, se reformó el Artículo 33 de la Constitución Política de los Estados Unidos Mexicanos que establecía desde 1917, que el Ejecutivo de la Unión tenía la facultad exclusiva de "hacer abandonar del territorio nacional", inmediatamente y "sin necesidad de juicio previo a todo extranjero" cuya permanencia juzgue "inconveniente", atribución que se modificó en 2011, exigiendo ahora "previa audiencia" para expulsar extranjeros. Por lo anterior, el Estado mexicano, solicitó, el retiro de la reserva al artículo 22, párrafo 4 de la Convención, por carecer de justificación una vez realizada la reforma constitucional de referencia como lo ha recomendado el mismo Comité al gobernó mexicano (CMW, Secretaría General de la ONU recibe petición del gobierno mexicano el día 110714)

No obstante, los esfuerzos del Estado mexicano, por ratificar e impulsar la protección de derechos humanos de los trabajadores migrantes y su familia, a octubre de 2017, México no ha adoptado según recomendación del CMW (CMW/C/MEX/ C/2, párr. 12) medidas para ratificar los convenios recogidos en tabla 3 :

Tabla 3. Acuerdos no ratificados por el Estado mexicano

\begin{tabular}{|c|}
\hline 1. El Convenio sobre los Trabajadores Migrantes (revisado), 1949 (OIT núm. 97) \\
\hline $\begin{array}{c}\text { 2. El Convenio sobre las Migraciones en Condiciones Abusivas y la Promoción de la Igualdad de } \\
\text { Oportunidades y Trato de los Trabajadores Migrantes, } 1975 \text { (OIT núm. 143) }\end{array}$ \\
\hline
\end{tabular}

Es importante resaltar, que si bien es necesario tener un marco normativo que establezca los límites y alcances de los derechos humanos de los trabajadores migrantes de conformidad a lo acordado por la comunidad internacional; las acciones formales del Estado mexicano son insuficientes para la protección de sus derechos humanos al celebrar más de diecisiete compromisos internacionales citados, renovar el mandato de relatores internacionales y aceptar comunicaciones de los particulares al CMW, ya que las resoluciones de relatores y organismos internacionales continúan insistiendo, en la violaciones graves de derechos humanos en el territorio nacional a migrantes trabajadores y sus familiares.

En este sentido, el Relator Especial sobre los Derechos Humanos de los Migrantes, (Relator Especial) en 2009, en su visita primera de dos visitas a México, recibió múltiples denuncias de migrantes, relativas a que en las estaciones migratorias, les han violado sus derechos humanos a los migrantes del tipo de tratos crueles, degradantes, hacinamientos, falta de atención médica, falta de higiene y de alimentos, acoso y abuso sexual cometido por el personal de las estaciones, personal de la marina o policía municipal.

Asimismo, en su segunda visita, en el Informe de 2011, el Relator Especial destaca también, que en los lugares de "aseguramiento" o "internamiento" se realizan torturas, no hay atención médica y no permiten comunicación a los migrantes con personas externas. También, hay reiterada omisión del Estado Mexicano de no "respetar" ni "garantizar" el ejercicio "libre y pleno" de los derechos humanos a todas las personas, sin distinción de 
origen, como son los migrantes, ni "tomar las medidas necesarias para hacer efectivos dichos derechos", por lo que constituyen violaciones a los compromisos internacionales como son del Pacto Internacional de Derechos Civiles y Políticos, artículo 2.1; de la Convención Americana sobre Derechos Humanos, artículos 1.1, 1.2 y 2; y de la Constitución Política de los Estados Unidos Mexicanos, artículo 1.

\subsection{Legislación}

Las normas de origen interno que el Estado mexicano ha expedido relativas a la migración para adecuarlas a las reformas constitucionales y los compromisos internacionales por la celebración de tratados como por el cumplimiento de recomendaciones de organismos internacionales, son las siguientes, tabla 4:

Tabla 4. Normas del Estado mexicano para adaptarse a los organismos internacionales

\begin{tabular}{|l|}
\hline $\begin{array}{l}\text { 1.La reforma de la Ley General de Población (LGP) que deroga las penas de prisión de } 18 \text { meses } \\
\text { hasta } 10 \text { años para los trabajadores migratorios indocumentados, en vigor desde el } 22 \text { de julio } \\
\text { de } 2008\end{array}$ \\
\hline 2.Ley para prevenir y sancionar la trata de personas \\
\hline 3.Ley General de Acceso de las Mujeres a una Vida Libre de Violencia \\
\hline $\begin{array}{l}\text { 4.Código Penal Federal, reformas para tipificar la trata de personas y la creación de la Fiscalía } \\
\text { Especial para Delitos de Violencia contra las Mujeres y Trata de Personas por recomendación } \\
\text { del CMW }\end{array}$ \\
\hline $\begin{array}{l}\text { 5.Reforma a la LGP, recepción de quejas a migrantes en materia de derechos humanos y la } \\
\text { procuración de justicia, 2010 }\end{array}$ \\
\hline 6.Ley sobre Refugiados y Protección Complementaria en enero de 2011 \\
\hline 7.Ley General para Prevenir y Sancionar los Delitos en materia de Secuestro \\
\hline $\begin{array}{l}\text { 8.Convenio Marco de colaboración para la prevención y el combate al secuestro de migrantes, } \\
\text { 2010 }\end{array}$ \\
\hline 9.Ley de Migración, del 25 de mayo de 2011 \\
\hline
\end{tabular}

No obstante, la expedición y reformas constantes al marco legislativo, creación y modificación de instituciones y sus funciones para proteger a los migrantes, continúa la comisión de violaciones graves de derechos humanos a los migrantes trabajadores y sus familiares, en éste sentido, se expidió recientemente una Ley de Migración, la cual prevé, que las "estaciones migratorias", son para "alojar temporalmente" a los migrantes mientras se resuelve su situación migratoria (Ley de Migración, artículos 89 y 99). Pero no obstante, estas disposiciones, el "internamiento" de los migrantes y sus familiares es en varios casos son prolongados. Por lo que recomienda el Comité de Trabajadores Migratorios y sus Familias, CMW, se limite dicho tiempo de "internamiento".

Del mismo modo, es importante resaltar, que se utiliza la palabra "internamiento" en lugar de la privación de su libertad personal de los migrantes, durante el tiempo que determinen su situación migratoria o en lugar de llamarle "detención", pues aunque en los dos casos, existe privación del derecho humano a la libertad personal, prevista la prohibición en el artículo 14 constitucional, en los términos siguientes: "Nadie podrá ser privado de la libertad...o derechos, sino mediante juicio seguido ante los tribunales previamente establecidos, en el que se cumplan las formalidades esenciales del procedimiento y conforme a las Leyes expedidas con anterioridad al hecho". Además, aunque existe desde 2008, las visitas de inspección por parte de la Secretaría del Trabajo, éstas no son suficientes para mejorar dichos lugares. En la mayoría de las estaciones de migración se carece de asistencia consular, por lo que esto 
fomenta los abusos y detenciones prolongadas de los migrantes. (Comité de Trabajadores Migratorios y sus Familias, 2011).

\subsection{Programas}

Las políticas públicas que son implementadas por el Estado mexicano para la protección de los derechos de los migrantes y sus familiares son mediante la publicación de Programas como los que aparecen en tabla 5:

Tabla 5. Programas para la protección de los migrantes y familias

\begin{tabular}{|c|}
\hline $\begin{array}{l}\text { 1. Programa Frontera Sur, implementado desde marzo de } 2008 \text {, que posibilita el otorgamiento de } \\
\text { las formas migratorias de trabajador fronterizo (FMTF) y de visitante local (FMVL) a } \\
\text { trabajadores migratorios guatemaltecos y beliceños }\end{array}$ \\
\hline 2. Programa de regularización migratoria vigente desde noviembre de 2008 hasta mayo de 2011 \\
\hline $\begin{array}{l}\text { 3.Manual de Criterios y Trámites Migratorios del Instituto Nacional de Migración (INM), enero } \\
2010\end{array}$ \\
\hline 4.Programa de Regularización Migratoria de 2011 \\
\hline $\begin{array}{l}\text { 5.Estrategia de prevención y atención a niños(as) y adolescentes migrantes y repatriados no } \\
\text { acompañados }\end{array}$ \\
\hline 6.La adopción de la Estrategia Integral para la Prevención y el Combate al Secuestro de Migrantes \\
\hline 7.El establecimiento del Grupo Técnico de Secuestro de Migrantes \\
\hline $\begin{array}{l}\text { 8.Los diferentes programas establecidos por el Estado para brindar asistencia a trabajadores } \\
\text { migratorios mexicanos en el exterior, así como las medidas adoptadas para facilitar la } \\
\text { reintegración de los trabajadores migratorios repatriados a México, como el portal electrónico } \\
\text { e-Migrantes, el programa de repatriación humana, y el Programa de Repatriación Voluntaria al } \\
\text { Interior }\end{array}$ \\
\hline 9.Programa Nacional para Prevenir y Sancionar la Trata de Personas \\
\hline $\begin{array}{l}\text { 10.Adopción por el Instituto Nacional de Migración (INM) de Protocolos para la detección, } \\
\text { identificación y atención a extranjeros víctimas de delitos y la posibilidad de otorgamiento de } \\
\text { visados para la estancia legal de víctimas y testigos de delitos }\end{array}$ \\
\hline $\begin{array}{l}\text { 11.Acuerdo por el que se emiten normas para el funcionamiento de las estaciones migratorias, en } \\
\text { vigor desde el } 8 \text { de octubre de } 2009\end{array}$ \\
\hline $\begin{array}{l}\text { 12. Conjunto de medidas adoptadas para mejorar las condiciones de las estaciones migratorias, para } \\
\text { reducir el hacinamiento y el tiempo de permanencia en las mismas, para facilitar el acceso a } \\
\text { asistencia médica, así como el acceso de los albergados a comunicación con el exterior }\end{array}$ \\
\hline
\end{tabular}

De lo anterior, podemos observar que no han faltado políticas públicas del Estado mexicano para la protección de derechos humanos de trabajadores migrantes y sus familias a partir de algunos programas citados, pero en los resultados no existe una "justicia efectiva" ya que las violaciones son graves de derechos humanos a los migrantes, las cuales son constantes y generalizadas, como lo podemos observar de los Informes de los Relatores Especiales en sus visitas a México (2002 y 2009), el Informe del Comité de Trabajadores Migratorios y sus Familias, CMW, en su visita a México de 2011, el Informe de la Comisión Interamericana de Derechos Humanos, CIDH, de 2013 en su visita a México y de manera específica en las veintisiete Recomendaciones especiales y una General de la Comisión Nacional de Derechos Humanos, CNDH, del periodo 1990 a 2017, en donde se califican violaciones graves como al derecho a la vida (Recomendaciones 64/2010, 3/2012, 80/2013, 2/2015), la prohibición de tortura, tratos crueles e inhumanos, privación a la integridad y libertad personal (en Recomendaciones 5/2005, 14/2006, 1/2007, 23/2006, 17/2014), el uso excesivo de la fuerza, el no respeto de la dignidad (Recomendación 17/2014), la prohibición de la discriminación, que por cierto es un derecho humanos de ius cogens, trata de personas, tráfico de personas, agresión sexual (Recomendaciones 54/2012 y 17/2014) migrantes a 
niños (Recomendaciones 25/2007, 57/2012, 54/2013, 17/2014 y 2/2015), mujeres (en Recomendaciones 63/2008, 17/2009, 54/2012, 17/2014, 2/2015), indígenas no solo de manera individual, sino a grupos de migrantes: 36 migrantes (23/2004), 46 migrantes (5/2005); 41 migrantes (14/2006), 5 migrantes (21/2006), 5 migrantes (36/2007), 34 migrantes (63/2008), 18 migrantes (65/2008), 65 migrantes (1/2009), 21 migrantes (50/2009), 132 migrantes (29/2009), 50 migrantes (32/2010) y 72 migrantes (80/2013).

Podemos observar, que no obstante los instrumentos internacionales celebrados por el Estado mexicano, las adecuaciones de leyes a dichos compromisos internacionales y publicación de programas de protección de derechos migrantes, la incidencia de violaciones continúa de 1990 a 2017 a pesar de las recomendaciones dictadas tanto por organismo internacionales como la Comisión Nacional de Derechos Humanos, ni porque se han emitido recomendaciones de no repetición, capacitación a servidores públicos sobre el respeto de derechos humanos de migrantes, solicitar el inicio de investigaciones y procedimientos administrativos de responsabilidad administrativa, la violación de derechos humanos continúan reportándose como violaciones graves, generalizadas y reiteradas a migrantes trabajadores y sus familias.

\section{RESOLUCIONES DE LA ASAMBLEA GENERAL DE NACIONES UNIDAS PARA LA PROTECCIÓN DE LOS TRABAJADORES MIGRANTES Y SU FAMILIA, 2002- 2015}

A continuación exponemos las resoluciones de la Asamblea General de las Naciones Unidas que aprobaron que el Consejo de Derechos Humanos y la Comisión de Derechos Humanos emitan once resoluciones relativas al tema de la protección de los derechos de los migrantes en el período de 2002 a 2015. Estas resoluciones, se exponen conforme a un orden temático, las cuales son vinculatorias para el Estado mexicano, al ser interpretaciones de órganos de vigilancia de aplicación de tratados por lo que son parte de estos instrumentos interpretaciones y por lo tanto, se integran al derecho interno. Iniciaremos definiendo cuáles son los instrumentos que se aplican en la protección de los derechos de los migrantes, cuáles son los grupos vulnerables (trabajadores migratorios y sus familias y mujeres y niños,) y los derechos humanos específicos, los sujetos de obligaciones y sus acciones con respecto a estos derechos, así como las reglas que emiten los diferentes órganos de Naciones Unidas para proteger a los migrantes y su familia.

\subsection{Instrumentos internacionales}

En la exposición de motivos de las resoluciones de referencia se fundamenta con la Declaración Universal de Derechos Humanos al reafirmar que todos los seres humanos nacen libres e iguales en dignidad y derechos y que toda persona tiene los derechos y libertades enunciados en ella sin distinción alguna así como que toda persona tiene derecho a circular libremente y a elegir su residencia en el territorio de un Estado, y a salir de cualquier país, incluso del propio, y regresar a su país. (ONU, Resolución 63/184, 2009: 1)

De manera específica, se enuncia que deben protegerse los derechos de los migrantes como la prohibición de la tortura, prohibición de la desaparición forzada de personas, la no discriminación de la mujer, la discriminación racial, el respeto al aviso consular, los derechos de la mujer, los del niño, los discapacitados, la lucha contra la delincuencia organizada, la trata de personas, el tráfico de personas entre otros a partir del cumplimiento de los instrumentos internacionales siguientes: el Pacto Internacional de Derechos Civiles y 
Políticos, el Pacto Internacional de Derechos Económicos, Sociales y Culturales, la Convención contra la Tortura y Otros Tratos o Penas Crueles, Inhumanos o Degradantes, la Convención Internacional para la Protección de Todas las Personas contra las Desapariciones Forzadas, la Convención sobre la Eliminación de Todas las Formas de Discriminación contra la Mujer, la Convención sobre los Derechos del Niño, la Convención Internacional sobre la Eliminación de Todas las Formas de Discriminación Racial, la Convención de Viena sobre Relaciones Consulares, la Convención sobre los Derechos de las Personas con Discapacidad, la Convención Internacional sobre la Protección de los Derechos de Todos los Trabajadores Migratorios y de sus Familiares, la Convención de las Naciones Unidas contra la Delincuencia Organizada Transnacional y sus protocolos, en particular el Protocolo contra el Tráfico Ilícito de Migrantes por Tierra, Mar y Aire, que complementa la Convención de las Naciones Unidas contra la Delincuencia Organizada Transnacional, y el Protocolo para Prevenir, Reprimir y Sancionar la Trata de Personas, Especialmente Mujeres y Niños, que complementa la Convención de las Naciones Unidas contra la Delincuencia Organizada Transnacional. (ONU, Resolución 29/2, 2015: 1-2) Asimismo, se reconoce la importancia del Diálogo de Alto Nivel sobre la Migración Internacional y el Desarrollo, de la Declaración del Diálogo de Alto Nivel sobre la Migración Internacional y el Desarrollo y el Foro Mundial sobre Migración y Desarrollo en sus distintas emisiones. (ONU, Resolución 26/21, 2014: 23)

\subsection{Grupos vulnerables}

La protección de los grupos vulnerables está previsto en las Resoluciones de la ONU de referencia, las cuales son de acuerdo con el Artículo 1 de la CPEUM, que señala que todas las personas son iguales ante la ley y también en dicha disposición fundamental, se prohíbe la discriminación por razón de origen. Por lo que, la Carta Fundamental protege también aquellas personas que se encuentran en una situación de desventaja ante las demás personas, para lo cual se prevé reglas de compensación para poner en la misma igualdad a esas personas en situación de desventaja, como son los trabajadores migrantes, mujeres, niños, que son previstos en la protección de las resoluciones de la ONU siguientes.

\subsubsection{Trabajadores migratorios}

La Comisión de Derechos Humanos de la ONU: alienta a los Estados de origen a que promuevan y protejan los derechos humanos de las familias de los trabajadores migrantes que permanecen en sus países de origen y prestando especial atención a los niños y adolescentes cuyos padres hayan emigrado; y alienta a las organizaciones internacionales a que consideren la posibilidad de prestar apoyo a los Estados a ese respecto (ONU, Resolución 2002/59, 2002: 1); insta además a los Estados a que, al concebir y aplicar la legislación y las políticas destinadas a brindar más protección a los derechos de los trabajadores, consideren la posibilidad de prestar una atención especial a la grave situación de falta de protección, y en algunos casos de explotación, de las personas objeto de trata, los migrantes clandestinos y los trabajadores domésticos objeto de tráfico ilícito (ONU, Resolución 2002/59, 2002: 1).

Pide a todos los Estados, la ONU que, de conformidad con su legislación nacional, sometan a juicio todos los casos de violación de las leyes laborales con respecto a las condiciones de trabajo de los trabajadores migrantes, en particular las relativas a su remuneración y a las condiciones de higiene y seguridad en el trabajo (Resolución 2002/59, 2002: 1). Hace hincapié en la necesidad de contar con información precisa, objetiva, exhaustiva y comparable, así como de realizar un amplio y sistemático intercambio de la 
experiencia adquirida por los países en lo que se refiere a la protección y la promoción de los derechos y el bienestar de las trabajadoras migrantes para la formulación de políticas y la adopción de medidas comunes (Resolución 2002/58, 2002: 1).

Invita la ONU a los gobiernos interesados, en particular los de los países de origen y de acogida, a que estudien la posibilidad de adoptar disposiciones legislativas apropiadas contra los intermediarios que alienten deliberadamente el movimiento clandestino de trabajadores y que exploten a las trabajadoras migrantes y violen su dignidad humana. Insta a los Estados a que velen por el pleno respeto y el cumplimiento de la Convención de Viena sobre Relaciones Consulares de 1963, especialmente en la medida en que guarda relación con el derecho de los nacionales extranjeros, cualquiera que sea su situación jurídica y de inmigración, a comunicarse con un funcionario consular de su propio Estado en caso de ser detenido o puesto en prisión preventiva y a que se le informe de ese derecho sin demora (Resolución 2002/58, 2002: 1).

La Asamblea General recuerda que en la Declaración del Milenio y la Cumbre Mundial 2005 se renovó el compromiso de adoptar medidas para asegurar el respeto y la protección de los derechos humanos de los migrantes incluidos los trabajadores migratorios (Resolución 60/169, 2006: 2). Alienta a los Estados de origen a que promuevan y protejan los derechos humanos de las familias de los trabajadores migrantes que permanecen en los países de origen, prestando especial atención a los niños y adolescentes cuyos padres hayan emigrado, $\mathrm{y}$ alienta a las organizaciones internacionales a que consideren la posibilidad de apoyar a los Estados a ese respecto (Resolución 60/169, 2006: 6).

La ONU pide a todos los Estados que, de conformidad con la legislación nacional y los instrumentos jurídicos internacionales aplicables en que sean partes, hagan cumplir efectivamente la legislación laboral, incluso ocupándose de las violaciones de dicha legislación, con respecto a las relaciones laborales y condiciones de trabajo de los trabajadores migratorios, entre otras, las relativas a su remuneración y las condiciones de higiene y seguridad en el trabajo y al derecho a la libertad de asociación (Resolución 60/169, 2006: 2).

La Asamblea menciona el informe sobre los períodos de sesiones séptimo y octavo del Comité de Protección de los Derechos de Todos los Trabajadores Migratorios y de sus Familiares (Resolución 63/184, 2009: 5). Recuerda que los trabajadores migrantes están entre las personas más afectadas y vulnerables en el contexto de las crisis financieras y económicas según el documento final de la Conferencia sobre la crisis financiera y económica mundial nombrada con anterior (Resolución 65/212, 2011: 2).

Reafirma el propósito de tomar nuevas medidas para asegurar el respeto y la protección de los derechos humanos de los migrantes, de los trabajadores migratorios y de sus familiares (Resolución 18/21, 2011: 2). Recuerda que las remesas se han visto afectadas negativamente por el aumento del desempleo y por el escaso crecimiento de los ingresos de esos trabajadores en algunos países de destino (Resolución 18/21, 2011: 2). Reconoce además que los migrantes que no están documentados o que se hallan en situación irregular son empleados frecuentemente en condiciones de trabajo menos favorables que las de otros trabajadores (Resolución 18/21, 2011: 3).

Asimismo reafirma que el Estado en que esté empleado un migrante tiene la obligación de velar por el respeto de los derechos humanos de ese trabajador en el ámbito laboral e insta a los Estados a que refuercen las medidas destinadas a proteger los derechos humanos de los trabajadores migratorios en momentos de crisis humanitaria (ONU, Resolución 18/21, 2011: $3)$. 
Reconoce que las trabajadoras migratorias contribuyen de manera importante al desarrollo social y económico de los países de origen y destino, mediante las repercusiones económicas y sociales de su trabajo, y subrayando el valor y la dignidad de su trabajo, incluido el de las trabajadoras domésticas. Exhorta a los Estados que aún no lo hayan hecho a velar por la protección de los derechos humanos de las trabajadoras migratorias, promover condiciones laborales justas y asegurar que todas las mujeres, incluidas las que trabajan como cuidadoras, estén legalmente protegidas de la violencia y la explotación (Resolución 67/172, 2013: 3).

Insta a los gobiernos a que combatan el trato injusto y discriminatorio de los migrantes, en particular de los trabajadores migratorios y sus familias y alienta a los Estados a poner en práctica políticas y programas para las trabajadoras migratorias atendiendo a las cuestiones de género, a proporcionar vías seguras y legales que reconozcan las aptitudes y la educación de las trabajadoras migratorias y faciliten su empleo productivo, trabajo decente e integración en la fuerza de trabajo, entre otras cosas en la educación y en la ciencia y la tecnología (Resolución 67/172, 2013: 3).

Por último, reconoce que las mujeres representan casi la mitad de todos los migrantes internacionales y reconoce también a este respecto que las trabajadoras migratorias contribuyen de manera importante al desarrollo social y económico de los países de origen y destino, y subrayando el valor y la dignidad de su trabajo, incluido el de las trabajadoras domésticas (Resolución 68/179, 2014: 3).

\subsubsection{Mujeres y niños}

La Asamblea General de las Naciones Unidas alienta a los Estados en conjunto con organizaciones no gubernamentales, sociedad civil e interesados emprendan campañas de información con el fin de explicar las oportunidades, limitaciones y derechos que van asociados a la migración para que estas personas en particular las mujeres y niños, puedan decidir con conocimiento de causa y para impedir que se transformen en víctimas de la trata de personas y que utilicen medios de acceso que pongan en peligro su vida y su integridad física. Recuerda la ONU, la vulnerabilidad de las mujeres haciendo mención de su resolución 55/25 de 15 de noviembre de 2000, de la Convención de las Naciones Unidas contra la Delincuencia Organizada Transnacional, del Protocolo contra el tráfico ilícito de migrantes por tierra, mar y aire y del Protocolo para prevenir, reprimir y sancionar la trata de personas (Resolución 2002/59, 2002: 1-2)

Asimismo, la Asamblea General de la ONU, observa que: el número de mujeres de países en desarrollo que deciden emigrar a países más prósperos ha aumentado debido a la carencia de estabilidad de la situación económica, política y social que es responsabilidad del Estado; alienta a los Estados a que estudien la posibilidad de firmar y ratificar o adherirse a la Convención Internacional sobre la protección de los derechos de todos los trabajadores migratorios y de sus familiares, la Convención de las Naciones Unidas contra la Delincuencia Organizada Transnacional y sus dos Protocolos Adicionales - el Protocolo contra el tráfico ilícito de migrantes por tierra, mar y aire y el Protocolo para prevenir, reprimir y sancionar la trata de personas, especialmente mujeres y niños-, así como la Convención sobre la esclavitud de 1926 (Resolución 2002/58, 2002: 1-2).

Se manifiesta preocupada la Asamblea General de la ONU: por el número creciente de mujeres y niños migrantes que se ponen a sí mismos en situación de vulnerabilidad al intentar cruzar las fronteras internacionales sin los documentos de viaje necesarios en particular los niños no acompañados o separados de sus padres (Resolución 68/179, 2014: 4); por las manifestaciones de violencia, racismo, xenofobia y otras formas de intolerancia y pide a los Estados que promuevan y protejan efectivamente los derechos humanos y las 
libertades fundamentales de todos los migrantes, especialmente de las mujeres y niños (ONU, Resolución 60/169, 2006: 3-4) sin importar su estatutos migratorio. Cabe resaltar que la Resolución 65/212 indica que la protección y promoción de los derechos humanos y libertades fundamentales son de conformidad con la Declaración Universal de Derechos Humanos y los instrumentos internacionales en que los Estados son partes (ONU, Resolución 65/212, 2011: 1). A la vez que la ONU los alienta a los Estados a que integren la perspectiva de género en la elaboración y aplicación de políticas y programas internacionales de migración a fin de adoptar las medidas necesarias para proteger mejor a las mujeres y niñas migrantes de los peligros y abusos a que están expuestas durante la migración (Resolución 65/212, 2011: 1).

Señala la ONU que muchas mujeres migrantes están empleadas en el sector no estructurado de la economía y en labores que requieren menos preparación en comparación con los hombres, lo cual da lugar a que esas mujeres se vean más expuestas al abuso y la explotación (ONU, Resolución 61/165, 2007: 2). De suma importancia, insta la Asamblea General de la ONU a los Estados que se ocupen de la migración internacional mediante la cooperación y el diálogo a escala internacional, regional o bilateral y la aplicación de un enfoque integral y equilibrado reconociendo las responsabilidades de los países de origen, tránsito y destino en la promoción y protección de los derechos de todos los migrantes (ONU, Resolución 63/184, 2009: 1).

Los países representados en la Asamblea General de la ONU expresa su preocupación por la intensificación de las actividades de las entidades de la delincuencia organizada transnacional y nacional, así como de otros que se lucran de los delitos contra los migrantes, especialmente mujeres y niños, sin importarles las condiciones peligrosas e inhumanas a que someten a sus víctimas y en flagrante violación de las leyes nacionales e internacionales y en contravención de las normas internacionales (ONU, Resolución 65/212, 2011: 1). Además se preocupa por el número elevado y en aumento de los migrantes, incluidos mujeres y niños que han perdido la vida o han resultado heridos intentando cruzar fronteras internacionales (ONU, Resolución 29/2, 2015: 2), y por otro lado, exhorta a los Estados a fortalecer las leyes, las instituciones y los programas nacionales para combatir la violencia de género, incluida la trata de personas y la discriminación contra las mujeres y las niñas (Resolución 29/2, 2015: 3).

\subsubsection{Sujetos de obligaciones}

A continuación se enumeran las obligaciones y responsabilidades de los Estados en el marco de protección y promoción de los derechos humanos de todos los migrantes incluidos mujeres, niños y trabajadores migrantes así como las exhortaciones y reglas que emite la Asamblea General y la Comisión de Derechos Humanos:

1. La Asamblea exhorta a los Estados a que faciliten la reunificación de las familias de modo expedito y eficiente,

2. Insta a los Estados a que, al concebir y aplicar la legislación y las políticas destinadas a brindar más protección a los derechos de los trabajadores, con una atención especial casos de explotación, de las personas objeto de trata, los migrantes clandestinos y los trabajadores domésticos objeto de tráfico ilícito. (Resolución 2002/59, 2011)

3. Velar por el pleno respeto y el cumplimiento de la Convención de Viena sobre Relaciones Consulares de 1963.

4. Alienta a los Estados a que estudien la posibilidad de firmar y ratificar o adherirse a la Convención Internacional sobre la protección de los derechos de todos los trabajadores 
migratorios y de sus familiares, la Convención de las Naciones Unidas contra la Delincuencia Organizada Transnacional y sus dos Protocolos Adicionales. (Resolución 2002/58, 2002)

5. Los Estados tienen las obligaciones reafirmadas en el fallo de la Corte Internacional de Justicia de 31 de marzo de 2004 en el caso Avena y otros nacionales mexicanos.

6. Están obligados a respetar los derechos humanos de los migrantes que cruzan las fronteras internacionales sin los documentos necesarios.

7. Insta a todos los Estados a que adopten medidas eficaces para poner término al arresto y la detención arbitrarios de migrantes y emprendan acciones para impedir y castigar cualquier tipo de privación ilegal de la libertad de los migrantes por individuos o grupos.

8. Insta también a todos los Estados a que empleen a funcionarios públicos debidamente autorizados y capacitados para aplicar sus leyes de inmigración y controles fronterizos. (Resolución 60/169, 2006)

9. Pide a todos los Estados que, de conformidad con la legislación nacional y los instrumentos jurídicos internacionales aplicables en que sean partes, hagan cumplir efectivamente la legislación laboral y actúen cuando se infrinja dicha legislación. (Resolución 61/165, 2007)

10. La Asamblea reconoce la importancia de que las leyes y reglamentos relativos a la migración irregular estén en consonancia con las obligaciones de los Estados en virtud del derecho internacional, incluidas las normas internacionales de derechos humanos.

11. Insta a todos los Estados a que adopten medidas eficaces para prevenir y castigar cualquier forma ilícita de privación de la libertad de los migrantes por parte de particulares o de grupos (Resolución 63/184, 2009)

12. Exhorta a todos los Estados a que respeten los derechos humanos y la dignidad intrínseca de los migrantes y pongan fin a los arrestos y detenciones de carácter arbitrario.

13. Subraya el derecho de los migrantes a regresar a su país de nacionalidad, y recuerda a los Estados que deben asegurar una acogida apropiada a los nacionales que regresen. (Resolución 65/212, 2011)

14. Insta a todos los Estados a que refuercen las medidas destinadas a proteger los derechos humanos de los trabajadores migratorios en momentos de crisis humanitaria. (Resolución 18/21, 2013)

15. Alienta también a los Estados a que sigan fortaleciendo su cooperación para la protección de los testigos en las acciones judiciales relacionadas con el tráfico ilícito de migrantes y la trata de personas. (Resolución 67/172, 2013)

16. Alienta a los Estados a tomar en consideración las necesidades y circunstancias concretas de los migrantes jóvenes reconociendo las contribuciones a los países de origen y de destino de estos. (Resolución 68/179, 2014)

17. Alienta a los Estados y a las organizaciones regionales e internacionales a que intensifiquen su cooperación con el Relator Especial. (Resolución 26/21, 2014)

De lo anterior, podemos observar que las resoluciones prevén las consideraciones acerca de la migración internacional como lo son las violaciones de los derechos humanos de quienes cruzan fronteras internacionales, el número en aumento de los sujetos participantes en la migración en busca de mejores oportunidades de trabajo, el número en aumento de niños incluidos los no acompañados en la dinámica migratoria así como los tratados, conferencias, documentos y foros en materia de protección de todos los migrantes. Teniendo en cuenta cada una de las consideraciones, por lo general, la Asamblea emite una serie de reglas específicas para los Estados donde exhorta a modificar sus políticas migratorias y a velar por la promoción y protección de los derechos humanos de todos los migrantes. Por 
último, recuerda tomar las recomendaciones de los Relatores Especiales e invita a los Estados a seguir colaborando en los estudios de campo.

\section{CONCLUSIONES}

El Estado mexicano a partir del marco normativo protege de manera formal, a los trabajadores migrantes y sus familias para lo cual reforma y adiciona la Constitución Política de los Estados Unidos Mexicanos; aprueba y celebra tratados internacionales; expide y reforma sus normas de origen interno, crea y modifica instituciones en cuanto a sus funciones y estructura, dicta políticas públicas mediante la publicación de programas, muchas veces por recomendaciones de organismos internacionales como Comité de Protección de los Derechos de todos los Trabajadores Migratorios y de sus Familiares (CMW), Resoluciones de la Asamblea de la ONU, Consejo de Derechos Humanos y Relatores Especiales en sus dos informes sobre México, la Comisión Interamericana de Derechos Humanos sobre temas de migración y visitas a México, y la Comisión Nacional de Derechos Humanos, CNDH, en el periodo de 1990 a 2017. Estos mismos organismos internacionales y la CNDH a través de sus informes, resoluciones y recomendaciones han resuelto que no es suficiente para la protección de los migrantes que "formalmente" se realicen todos estos actos citados por el Estado mexicano, pues en la realidad no se cumplen los compromisos internacionales y legislación interna de protección de migrantes, por lo que informan que en México no hay "justicia efectiva" ya que las violaciones de derechos humanos de los trabajadores migrantes y sus familia son violaciones graves, generalizadas, reiteradas del tipo del derecho a la vida, a la prohibición de la tortura, a la desaparición forzada de personas, a la no discriminación de la mujer, a la no discriminación racial, al trato digno, a la integridad y libertad personal, al debido proceso bajo la modalidad del aviso consular, los derechos de la mujer, del niño, la trata de personas y el tráfico de personas, previstos en el marco normativo interno y externo.

\section{BIBLIOGRAFÍA}

Iglesias, A. (2013) Trata de Mujeres con fines de explotación sexual. Valencia: Tirant lo Blanch.

Ortiz, L (2011) El Derecho de Acceso a la Justicia de los Inmigrantes en Situación Irregular. México: UNAM.

Pérez, C. (2014) Derecho Internacional y Protección de Mujeres Migrantes en Situación Especial de Vulnerabilidad. Valencia: Tirant lo Blanch.

Prado Carrera, G. (2017) "Los Derechos Humanos de los Migrantes". Perfiles de las Ciencias Sociales, 4 (8): 240-258.

Téllez, E. (2014) Derecho Internacional en la Práctica Latinoamericana. México: UNAM-Tirant lo Blanch.

\section{Acuerdos o convenciones internacionales}

Convención de las Naciones Unidas contra la Delincuencia Organizada Transnacional, ratificados DOF 4 de marzo de 2003.

Convención de Viena sobre Relaciones Consulares (DOF 20 de febrero 1965).

Convención Internacional para la Protección de Todas las Personas contra la Desapariciones Forzadas, ratificada el 18 de marzo de 2008.

Convención Internacional sobre la Eliminación de Todas las Formas de Discriminación Racial, (DOF 13/05/1975). 
Convención Internacional sobre protección de los derechos de todos los trabajadores migratorios y sus familiares (AG resolución 45/158, DOF 18 de diciembre de 1990).

Convención sobre la eliminación de todas las formas de discriminación contra la mujer, (DOF 12/05/1981).

Convención sobre los derechos de las personas con discapacidad, ratificada el 17 de diciembre de 2007 y su Protocolo Facultativo.

Convención Sobre los Derechos del Niño. (DOF.25/01/1995).

Convenio relativo a la abolición del trabajo forzoso, 1957 (No. 105).

Convenio relativo al trabajo forzoso u obligatorio, 1930 (No. 29).

Declaración Universal de Derechos Humanos, (10/12/1948).

Pacto Internacional de Derechos Civiles y Políticos, (DOF 20 de mayo de 1981).

Pacto Internacional de Derechos Económicos, Sociales y Culturales (DOF 12 mayo de 1981).

Protocolo contra el Tráfico Ilícito de Migrantes por Tierra, Mar y Aire (DOF 10 abril 2003).

Protocolo Facultativo de la Convención contra la Tortura y Otros Tratos o Penas Crueles, Inhumanos o Degradantes, ratificado el 11 de abril de 2005.

Protocolo para prevenir, reprimir y sancionar la de Personas, especialmente Mujeres y Niños (DOF 10 abril 2003).

Recomendación sobre los trabajadores migrantes (No. 86).

Recomendación sobre los trabajadores migrantes (No.151).

Segundo Protocolo Facultativo del Pacto Internacional de Derechos Civiles y Políticos relativo a la abolición de la pena de muerte, en 2007.

\section{Legislación interna}

Constitución Política de los Estados Unidos Mexicanos (DOF 05/02/1917) (Reforma 24/02/2017).

Ley de Migración (DOF.25/05/2011) (Reforma 21 de abril de 2016).

Ley del Registro Nacional de Datos de Personas Extraviadas o Desaparecidas (DOF 17 abril 2012).

Ley Federal del Trabajo (DOF.01/04/1970( (Reforma 12/06/2015).

Ley General de Acceso de las Mujeres a una Vida Libre de Violencia (DOF 17 de diciembre 2015).

Ley General de los Derechos de las Niñas, Niños y Adolescentes; Nueva (DOF 4 de diciembre de 2014).

Ley General de los Derechos de Niñas, Niños y Adolescentes (DOF 4 de diciembre 2014).

Ley General para Prevenir, Sancionar y Erradicar los Delitos en Materia de Trata de Personas y para la Protección y Asistencia a las Víctimas de Estos Delitos (DOF 14/06/2012) (Reforma 19 de marzo 2014).

Ley para la Protección de los Derechos de Niñas, Niños y Adolescentes (DOF 29/05/2000) (Reforma 05/12/2014) Abrogada.

Reglamento de la Ley de Migración (DOF 28/09/2012) (Reforma 24/05/2014).

\section{Programas}

Programa de Regularización Migratoria (temporal) (DOF 11/10/2016.

Programa Especial de Migración 2014-2018. (DOF 30/04/2014).

Programa Nacional de Derechos Humanos 2014-2018 (DOF 30/04/2014).

\section{Resoluciones de la ONU}

Comité de Trabajadores Migratorios y sus Familias. CMW (2010) $13^{\circ}$ periodo de sesiones. Observaciones Generales, №. 1.

Comité de Trabajadores Migratorios y sus Familias, CMW (2011) Informe de México.

Relator Especial sobre los derechos humanos de los migrantes (2009) Misión a México.

Relator Especial sobre los derechos humanos de los migrantes (2002) Misión a México.

Resolución 2002/58 (2002a) Asamblea General de Naciones Unidas, E/CN.4/2002/200. Relativa a la Violencia contra las trabajadoras migrantes. Asamblea General de Naciones Unidas. Aprobada por la Comisión de Derechos Humanos el 25 de abril de 2005 en su $55^{\circ}$ período de sesiones. 
Resolución 2002/59 (2002b) Asamblea General de las Naciones Unidas E/CN.4/2002/200. Aprobada por la Comisión de Derechos Humanos el 25 de abril de 2005 en su $55^{\circ}$ período de sesiones.

Resolución 60/169 (2006) de la Asamblea General de Naciones Unidas, A/RES/60/169, relativa a la Protección de los migrantes, aprobada por la Asamblea General el 16 de diciembre de 2005 en su $64^{\circ}$ período de sesiones.

Resolución 61/165 (2007) de la Asamblea General de Naciones Unidas, A/RES/61/165, relativa a la Protección de los migrantes, aprobada por la Asamblea General el 19 de diciembre de 2006 en su $81^{\circ}$ sesión plenaria.

Resolución 63/184 (2009) de la Asamblea General de Naciones Unidas, A/RES/63/184, relativa a la Protección de los migrantes, aprobada por la Asamblea General el 18 de diciembre de 2008 en su $70^{\circ}$ sesión plenaria.

Resolución 18/21 (2011) de la Asamblea General de Naciones Unidas, A/HRC/RES/18/21, relativa a Los derechos de los migrantes, aprobada por el Consejo de Derechos Humanos el 30 de septiembre de 2011 en su $37^{\circ}$ sesión.

Resolución 65/212 (2011) de la Asamblea General de Naciones Unidas, A/RES/65/212, relativa a la Protección de los migrantes, aprobada por la Asamblea General el 21 de diciembre de 2010 en su $71^{\circ}$ sesión plenaria.

Resolución 67/172 (2013) de la Asamblea General de Naciones Unidas, A/RES/67/172, relativa a la Protección de los migrantes, aprobada por la Asamblea General el 20 de diciembre de 2012 en su $60^{\circ}$ sesión plenaria.

Resolución 68/179 (2014) de la Asamblea General de Naciones Unidas, relativa a la Protección de los migrantes, A/RES/68/179, aprobada por la Asamblea General el 18 de diciembre de 2013 en su $70^{\circ}$ sesión plenaria.

Resolución 26/21 (2014) de la Asamblea General de Naciones Unidas, relativa a la Promoción del derecho de los migrantes al disfrute del más alto nivel posible de salud física y mental, A/HRC/RES/26/21, aprobada por el Consejo de Derechos Humanos el 27 de junio de 2014 en su $39^{\circ}$ sesión.

Resolución 29/2 (2015) de la Asamblea General de Naciones Unidas, relativa a la Protección de los derechos humanos de los migrantes: migrantes en tránsito, A/HRC/RES/29/2, aprobada por el Consejo de Derechos Humanos el 2 de julio de 2015 en su $42^{\circ}$ sesión.

\title{
Resoluciones de la OEA
}

Comisión Interamericana de Derechos Humanos, CIDH, (2013) Informe sobre migrantes en México.

\begin{abstract}
Recomendaciones de la Comisión Nacional de Derechos Humanos (México)
Comisión Nacional de Derechos Humanos, CNDH, Recomendación 23/2004 del 5/04/2004.

Comisión Nacional de Derechos Humanos, CNDH, Recomendación 5/2005 del 28/03/2005.

Comisión Nacional de Derechos Humanos, CNDH, Recomendación 14/2006 del 18/05/2006.

Comisión Nacional de Derechos Humanos, CNDH, Recomendación 21/2006 del 21/06/2006.

Comisión Nacional de Derechos Humanos, CNDH, Recomendación 23/2006 del 21/06/2006.

Comisión Nacional de Derechos Humanos, CNDH, Recomendación 1/2007 del 18/01/2007.

Comisión Nacional de Derechos Humanos, CNDH, Recomendación 25/2007 del 10/07/2007.

Comisión Nacional de Derechos Humanos, CNDH, Recomendación 36/2007 del 5/09/2007.

Comisión Nacional de Derechos Humanos, CNDH, Recomendación 63/2008 del 19/12/2008.

Comisión Nacional de Derechos Humanos, CNDH, Recomendación 65/2008 del 20/12/2007.

Comisión Nacional de Derechos Humanos, CNDH, Recomendación 17/2009 del 6/03/2009.

Comisión Nacional de Derechos Humanos, CNDH, Recomendación 29/2009 del 6/05/2009.

Comisión Nacional de Derechos Humanos, CNDH, Recomendación 50/2009 del 4/08/2009.

Comisión Nacional de Derechos Humanos, CNDH, Recomendación 32/2010 del 8/06 2010.

Comisión Nacional de Derechos Humanos, CNDH, Recomendación 64/2010 del 27/10/ 2010.

Comisión Nacional de Derechos Humanos, CNDH, Recomendación 3/2012 del 8 /02/2012.

Comisión Nacional de Derechos Humanos, CNDH, Recomendación 54/2012 del 28/09/2012.

Comisión Nacional de Derechos Humanos, CNDH, Recomendación 57/2012 del 18/10/2012.
\end{abstract}


Comisión Nacional de Derechos Humanos, CNDH, Recomendación 80/2013 del 23/12/2013. Comisión Nacional de Derechos Humanos, CNDH, Recomendación 17/2014 del 29/04/2014. Comisión Nacional de Derechos Humanos, CNDH, Recomendación 2/2015 del 30/01/2015.

\section{Breve currículo:}

\section{Alfredo Islas Colín}

Profesor Investigador Nacional, Miembro del Sistema Nacional de Investigadores del CONACYT, nivel III; Doctor en Derecho Constitucional por la Université Panthéon-Assas, París II; Maestría en Derecho Constitucional por la misma Universidad de París II; Maestría en Derecho Constitucional por la Universidad de Castilla-La Mancha; y la Licenciatura en Derecho por la Facultad de Derecho de la UNAM. Profesor de la Universidad Juárez Autónoma de Tabasco. 